\title{
Effects of Thickness of Electroless Ni-P Deposit on Corrosion Fatigue Damage of 7075-T6 under Salt Spray Atmosphere
}

\author{
Cheng-Hsun $\mathrm{Hsu}^{1}$, Sheng-Chien $\mathrm{Chiu}^{2}$ and Yih-Hsun Shih ${ }^{3}$ \\ ${ }^{1}$ Professor, Department of Materials Engineering, Tatung University, Taipei, Taiwan 104, R.O.China \\ ${ }^{2}$ Department of Materials Engineering, Tatung University, Taipei, Taiwan 104, R.O.China \\ ${ }^{3}$ Department of Metal Mold Tao-Yen Vocational High School, Tao-Yen, Taiwan 330, R.O.China
}

Fatigue tests under reversed flexure have been conducted on samples of 7075-T6 Al-alloy with the application of electroless Ni-P deposits of thickness ranging from 5 to $50 \mu \mathrm{m}$ after salt spray corrosion (100, 500 and 1000 hours). The corrosion damage of the coated and uncoated samples was determined through the measurement of the mass loss and surface corroded morphology. The mean microhardness of the high phosphorous (Hi-P) deposits in 5, 25 and $50 \mu \mathrm{m}$ thickness were found to be 334, 457 and $606 \mathrm{Hv}_{50}$, and the mean surface roughness (Ra) were measured at $0.197,0.217$ and $0.223 \mu \mathrm{m}$ for 5,25 and $50 \mu \mathrm{m}$ thickness, respectively. The salt spray tests revealed that the corrosion damage increases as the exposure time increases for the $5 \mu \mathrm{m}$ coating. The corrosion damage literally stopped when the coating thickness was increased to $25 \mu \mathrm{m}$. The fatigue strength of the coated samples was found decrease slightly as the deposit thickness increases to $25 \mu \mathrm{m}$, whereas the reduction on the fatigue strength for the $50 \mu \mathrm{m}$ deposit is significant. It has been observed that the reduction in the fatigue strength is less or to none for the thicker coating system. For the $5 \mu \mathrm{m}$ Hi-P deposit sample, the fatigue crack initiation started at the surface corrosion pitting then extending to the substrate and onto failure, this phenomenon reduced the fatigue strength as compared to the uncoated samples. The fatigue strength is decreased slightly as the thickness increases to $25 \mu \mathrm{m}$ and $50 \mu \mathrm{m}$. With or without corrosion damage, the fatigue crack initiation all started from the coating and extended to the substrate through the bonding between the coating and the substrate. Balancing between the need for the corrosion resistance and the fact on the fatigue strength reduction, the optimum coating thickness seems to be greater than $5 \mu \mathrm{m}$ but less than $25 \mu \mathrm{m}$ for the aerospace alloy 7075-T6 Al-alloy.

(Received June 15, 2004; Accepted September 21, 2004)

Keywords: 7075-T6 Al-alloy, electroless nickel-phosphorus deposit, coating thickness, corrosion, fatigue strength

\section{Introduction}

The pronounced reduction of fatigue strength caused by salt pitting corrosion or corrosion fatigue in a marine environment is well established for both steel and Al-alloy materials. ${ }^{1-4)}$ Fatigue crack initiatory sites commonly occurred in corrosion pitting area in the Al-alloys widely used for structural components of aircraft. Pit arose from the intergranular corrosion to a depth depends upon the service environment and the time of exposure, i.e., service conditions of the aircraft. According to Agarawala's report, ${ }^{5)}$ the worldwide annual expenditure for corrosion inspection and repair of military aircraft alone is estimated to exceed one billion US dollars. Currently, more military and civilian aircrafts are expected to exceed a 20 -year service life by the years to come. Thus, a means of mitigating corrosion and corrosion-related fatigue damage is very significant and needed for obtaining the destination.

Electroless Ni-P (EN) deposits have a wide field of application, particularly in the industrial components and machine parts. However, it is offered in some literatures ${ }^{6-8)}$ that electroless coatings may give rise to a reduction in the fatigue properties of the substrate depending on the residual stresses induced by the deposit. In relation to EN coatings, it has also been reported ${ }^{9-12)}$ that the fatigue properties of steels can be deteriorated if such coatings have less than $10 \% \mathrm{P}$ contents will induce tensile residual stresses in the deposits. On the contrary, if these deposits contain higher P contents will induce compressive residual stresses. Some studies ${ }^{13-15)}$ have reported that there is an increase in the fatigue life of steels coated with EN deposits of $12 \% \mathrm{P}$ without post-heat treatment (PHT). PHT commonly applied to EN deposits produces significant increases in hardness, which contributes to improve the wear resistance of the coated parts and components. The PHT, however, can also have a harmful effect on the fatigue properties of such parts. It has been found ${ }^{6,9,12,13,16)}$ that can give rise to decrease the fatigue life of steels possibly as a consequence of precipitation of $\mathrm{Ni}_{3} \mathrm{P}$ particles, which are believed to induce tensile residual stresses in the deposits. According to these researches, EN deposits containing different $\mathrm{P}$ contents may give rise to a decrease or increase in the fatigue life of the substrate. Therefore, it is interested for this study to further explore the effects of the EN coating thickness and $\mathrm{P}$ contents on the corrosion and fatigue behaviors, particularly through the salt spray test, of 7075-T6 Al-alloy without PHT to the deposit.

\section{Experimental Procedures}

In this experiment, commercial plate of 7075-T6 Al-alloy was used as the substrate and chemical composition of the material is given in Table 1. Specimen for fatigue tests was machined according to ASTM E466 specification ${ }^{17)}$ with a gauge diameter of $8 \mathrm{~mm}$ and a gauge length of $25 \mathrm{~mm}$. The procedure for generating the $\mathrm{S}-\mathrm{N}$ data common used the rotating bending test. Fatigue tests were carried out under

Table 1 Chemical composition of the experimental material (mass $\%$ ).

\begin{tabular}{ccccccccccccc}
\hline Element & $\mathrm{Zn}$ & $\mathrm{Mg}$ & $\mathrm{Cu}$ & $\mathrm{Fe}$ & $\mathrm{Si}$ & $\mathrm{Mn}$ & $\mathrm{Cr}$ & $\mathrm{Ti}$ & & $\mathrm{Al}$ & & \\
\hline mass$\%$ & $5.1 \sim 6.1$ & $2.1 \sim 2.9$ & $1.2 \sim 2.0$ & $<0.5$ & $<0.4$ & 0.3 & $0.2 \sim 0.3$ & 0.20 & $\mathrm{Bal}$. & & \\
\hline
\end{tabular}


stress-controlled conditions in ambient temperature and operated at a frequency of $2000 \mathrm{rpm}$. The stress ratio is a constant value $(R=-1)$. The largest stress amplitude of $240 \mathrm{MPa}$ was determined from the yield stress (average $480 \mathrm{MPa}$ ) obtained from tensile test. The term fatigue strength is used to specify a stress amplitude value from an $\mathrm{S}-\mathrm{N}$ curve at a particular life of interest. Hence, the fatigue strength at $1.0 \times 10^{7}$ cycles is simply the stress amplitude corresponding to $N_{\mathrm{f}}=10^{7}$. There are four conditions in the investigation, namely, un-coated specimen and the EN coating specimens of $5 \mu \mathrm{m}, 25 \mu \mathrm{m}$ and $50 \mu \mathrm{m}$ in thickness, respectively. The fatigue behaviors of EN coating specimens were compared with uncoated specimen after 3 various time intervals of salt spray tests. In addition, according to ASTM E8M standard, ${ }^{18)}$ the specimen of tensile test was machined to have a gauge square $6 \times 6 \mathrm{~mm}^{2}$ and a gauge length of $32 \mathrm{~mm}$. Three tests were done at a constant strain-rate of $1 \times 10^{-3} \mathrm{~s}^{-1}$, and averaged to represent the tensile properties of the specimens in each condition. Also, some complementary samples were prepared for the evaluation of the EN coatings in micro-hardness, adhesion, surface roughness, thickness and chemical composition.

Before EN coating, the pre-coating specimens were ground with grit size 600-1200 SiC paper. Subsequently, all the specimens were mechanically polished in order to get the consistent surfaces. The polished specimens were then degreased, rinsed in distilled water, ultrasonically cleaned with alcohol for 10 minutes, rinsed with deionized water, and finally dried in hot air. The chemical composition of the plating bath has been adopted by some reports ${ }^{19}$ ) and consisted of $21 \mathrm{~g} / \mathrm{L}$ of nickel chloride, $24 \mathrm{~g} / \mathrm{L}$ of sodium hypophosphite, $30 \mathrm{~g} / \mathrm{L}$ ammonium chloride and $45 \mathrm{~g} / \mathrm{L}$ sodium citrate. The deposition of higher phosphorous (Hi-P) content was conducted at a $\mathrm{pH}$ value of 4.8 and $361 \mathrm{~K}\left(88^{\circ} \mathrm{C}\right)$ for maintaining a plating rate of approximately $11 \mu \mathrm{m} / \mathrm{h}$. Similarly, the deposition of lower phosphorus (Lo-P) content was conducted at a $\mathrm{pH}$ value of 5.0 and $361 \mathrm{~K}$ for maintaining a plating rate of approximately $18 \mu \mathrm{m} / \mathrm{h}$. The solution was continuously agitated using a circulating pump. Both the volume and $\mathrm{pH}$ of the bath were maintained by adding continuously a solution of $10 \% \mathrm{KOH}$. For comparing the effect of $\mathrm{P}$ contents on deposit characteristics, it respectively expended $150 \mathrm{~min}$ depositing time for the Hi-P and $85 \mathrm{~min}$ for the Lo-P to obtain the same thickness deposits of $25 \mu \mathrm{m}$. Further, one of the both resulting coatings, possessing the better adhesion, was preferred the base on $\mathrm{P}$ contents to deposit the coatings of 5, 25 and $50 \mu \mathrm{m}$ thickness, respectively, and then evaluated the corrosion and fatigue behaviors of 7075-T6 after salt spray test.

The chemical composition of the resulting deposits was analyzed with a glow discharge spectrometer (GDS, LECO750). Surface texture of the deposits was analyzed by using an X-ray diffractometer (XRD, Rigaku D/MAX-3A) with $\mathrm{Cu}$ $\mathrm{K} \alpha$ radiation at $40 \mathrm{kV}$ and $20 \mathrm{~mA}$. Microhardness tests were carried out in Akashi Vickers microhardness tester with a load of $50 \mathrm{gf}$. Five hardness readings were taken and averaged to represent the HV value of the coating hardness. A profilometer Surfacorder Analyzer (model AY- 41) was used to measure the surface roughness ( $\mathrm{Ra}$ value) of the coated and uncoated specimens. Corrosion current $\left(I_{\text {corr }}\right.$.) obtained from the polarization curve is an experimental potentiostatic anodic polarization. Scanning electron microscopy (SEM, JEOL JSM-5600) was used to observe the surface morphology and thickness of the deposits. Adhesion strength and adhesive failure mechanism were analyzed by using an acoustic emission machine (CSEM Revetest) at a loading rate of $1.67 \mathrm{~N} / \mathrm{s}$ with a scratch length of $10 \mathrm{~mm}$. Also, a Rockwell-C indenter with a load of $980 \mathrm{~N}$ was utilized to analyze and compare the surface adhesion of EN deposits. ${ }^{20)}$

According to ASTM G85 ${ }^{21)}$ and ASTM B117 standards, ${ }^{22)}$ a salt spray tester (model GSST-060) was utilized to perform corrosion damage test in this work. The testing conditions mainly consisted of 5 mass $\% \mathrm{NaCl}$ liquid solution and testing temperature of $308 \mathrm{~K}\left(35^{\circ} \mathrm{C}\right)$. After salt spray exposure of $100 \mathrm{~h}, 500 \mathrm{~h}$ and $1000 \mathrm{~h}$, respectively, the pre-fatigue specimens were washed with Clark's solution $\left(\mathrm{H}_{2} \mathrm{Cl}+20 \mathrm{~g} / \mathrm{L}\right.$ $\mathrm{Sb}_{2} \mathrm{O}_{3}+50 \mathrm{~g} / \mathrm{L} \mathrm{SnCl}_{2}$ ) for removing the surface corrosives, and then rinsed with distilled water before drying. Corrosion damage was documented both in terms of the mass loss and the corrosion current. Surface corroded morphology was examined by optical microscopy with low and high magnifications. Pitting distribution was measured at high magnification using SEM after removal of the surface layer of oxide corrosion product with nitric acid.

\section{Results and Discussion}

\subsection{Characteristics of Hi-P and Lo-P Deposits}

In this work, the $\mathrm{P}$ content of the Hi-P and Lo-P deposits in $25 \mu \mathrm{m}$ thickness were determined by the profile analysis using GDS, as presented in Fig. 1 and listed in Table 2. Figure 2 illustrates the XRD patterns of uncoated and EN coated specimens. It has been found that in spite of the different $\mathrm{P}$ contents, both structures of the Hi-P and Lo-P deposits were amorphous type in the as-deposited condition. However, the coating properties of Hi-P deposit in hardness, surface roughness, and corrosion resistance are better than those of Lo-P deposit. These measured data are also listed in Table 2.

Figure 3 shows the SEM observance of surface fractured by Rockwell indenter for the Hi-P and Lo-P deposits. It can be seen that the Hi-P deposit showed a smooth and complete punched surface, while the Lo-P deposit had a radial crack marks ridden punched surface. According to the referenced papers, ${ }^{20,23)}$ the adhesion strength for the Hi-P indeed is higher than the Lo-P. Furthermore, the adhesion strength and adhesive failure mechanism analysis could be corroborated by means of the acoustic emission patterns along the scratch tracks under an increasing load $(0 \sim 100 \mathrm{~N})$ and at a load rate of $1.67 \mathrm{~N} / \mathrm{s}$ with a scratch length of $10 \mathrm{~mm}$, as shown in Fig. 4, respectively. The Lo-P coating started to have response signal which indicates the existence of a high load induced distorted coating at $0.5 \mathrm{~mm}$ into the scratch test, while for the Hi-P coating indicated that only at $1 \mathrm{~mm}$ did the scratch track start showing the distorted coating. Comparing the adhesion strength of the Hi-P and Lo-P, not only the surface distortion is less for the Hi-P but also there was no debonding or cracking than the Lo-P. The polarization corrosion test for the Hi-P and Lo-P were showed in Table 2 and Fig. 5. The corrosion current $\left(I_{\text {corr }}\right)$ for the Hi-P and 

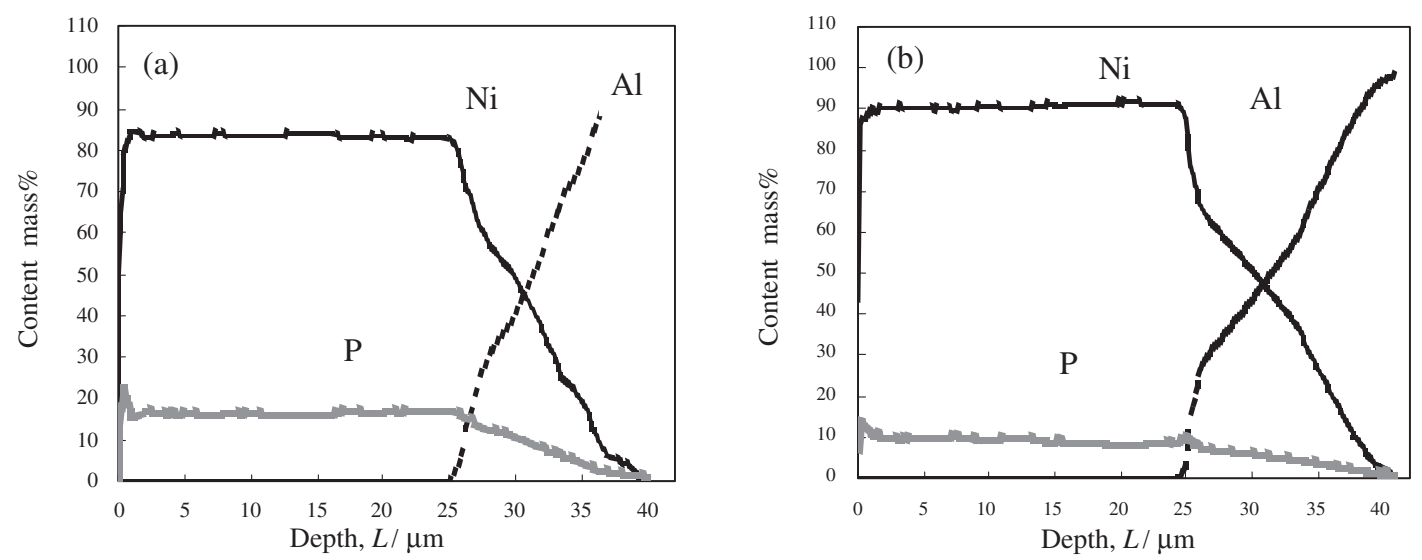

Fig. 1 GDS patterns for $25 \mu \mathrm{m}$ thickness specimens of $\mathrm{P}$ and Ni contents: (a) Hi-P; (b) Lo-P.

Table 2 Effect of $\mathrm{P} \%$ on characteristics of EN coatings in $25 \mu \mathrm{m}$ thickness.

\begin{tabular}{cccccc}
\hline Specimen & $\begin{array}{c}\text { P content } \\
(\text { mass } \%)\end{array}$ & Structure & $\begin{array}{c}\text { Hardness } \\
(\mathrm{Hv})\end{array}$ & $\begin{array}{c}\text { Ra value } \\
(\mu \mathrm{m})\end{array}$ & $\begin{array}{c}\text { Polarization current, } I_{\text {corr. }} \\
\left(\mu \mathrm{A} / \mathrm{cm}^{2}\right)\end{array}$ \\
\hline Hi-P & $15 \pm 0.5$ & Amorphous & 457 & 0.217 & 0.50 \\
\hline Lo-P & $8 \pm 0.5$ & Amorphous & 383 & 0.295 & 0.95 \\
\hline
\end{tabular}

\section{(a)}

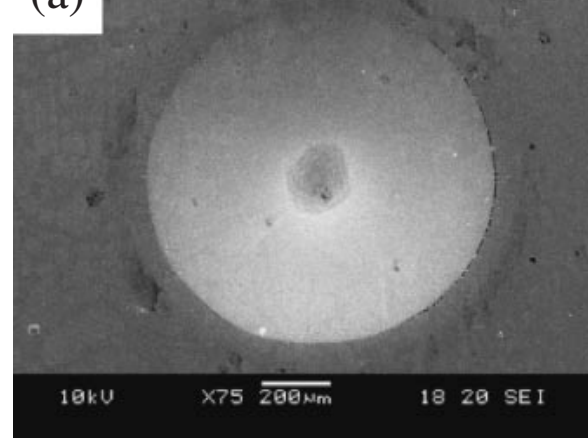

(b)

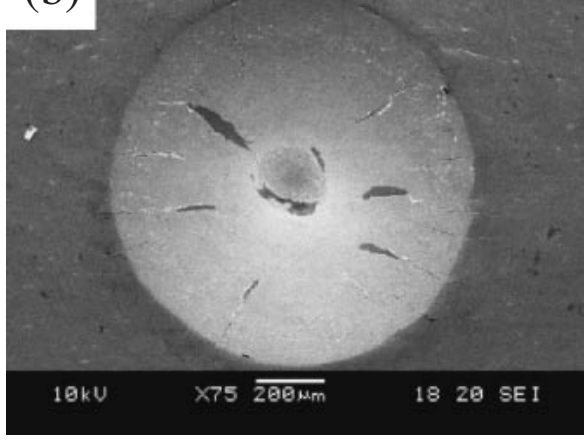

Fig. 3 Indented marks of $25 \mu \mathrm{m}$ EN coating thickness by Rockwell-C tester: (a) Hi-P; (b) Lo-P.

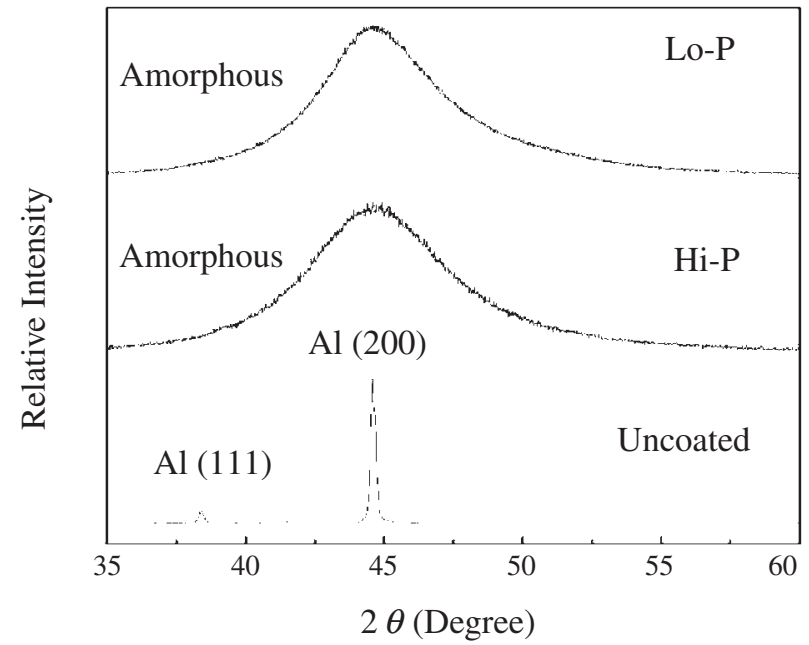

Fig. 2 XRD Patterns for $25 \mu \mathrm{m}$ coating thickness of Lo-P, Hi-P and uncoated 7075-T6 Al-alloy.

Lo-P coatings was 0.5 and $0.95 \mu \mathrm{A} / \mathrm{cm}^{2}$, respectively. The amorphous contents will be higher in the EN deposit structure when the $\mathrm{P}$ content is higher and the corrosion resistance was
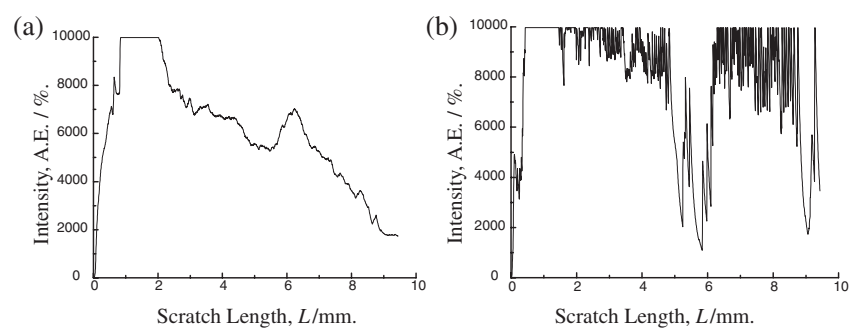

Fig. 4 Acoustic emission patterns for specimens of $25 \mu \mathrm{m}$ coating thickness: (a) Hi-P; (b) Lo-P.

also better. ${ }^{24)}$

It was concluded at this point that the Hi-P is superior to the Lo-P in depositing characteristics, thus it was chosen for the further studies. It was found that the deposition time of 30,150 and 300 minutes for Hi-P specimens produce a depositing thickness approximately of $5,25,50 \mu \mathrm{m}$, respectively.

\subsection{Evaluation of corrosion damage}

Table 3 summarizes the mass loss (mg) after the different 


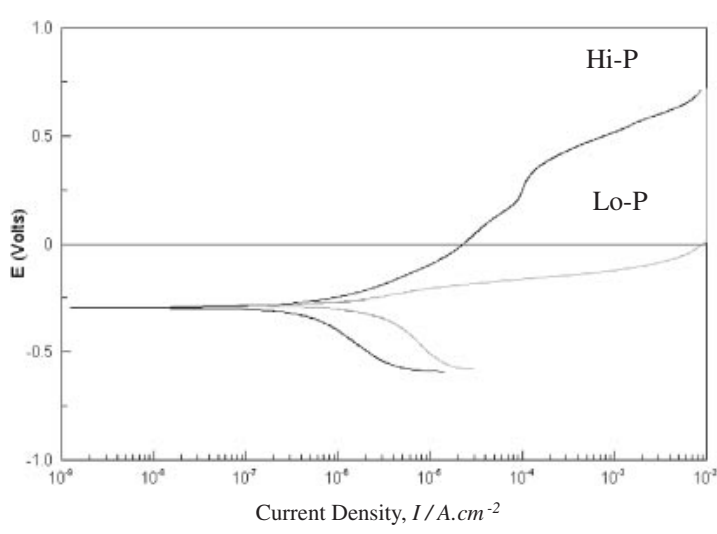

Fig. 5 Polarization curves for Hi-P and Lo-P specimens of $25 \mu \mathrm{m} \mathrm{EN}$ coating thickness.

Table 3 Mass loss (mg) of 7075-T6 with and without various thickness EN coatings after salt spray test of the different time.

\begin{tabular}{rllll}
\hline \multirow{2}{*}{$\begin{array}{c}\text { Corrosion } \\
\text { time }\end{array}$} & Un-coated & \multicolumn{3}{c}{ EN coating thickness } \\
\cline { 3 - 5 } & & $5 \mu \mathrm{m}$ & $25 \mu \mathrm{m}$ & $50 \mu \mathrm{m}$ \\
\hline $0 \mathrm{~h}$ & 0 & 0 & 0 & 0 \\
\hline $100 \mathrm{~h}$ & 0.721 & 0.054 & 0 & 0 \\
\hline $500 \mathrm{~h}$ & 2.738 & 0.236 & 0.007 & 0.007 \\
\hline $1000 \mathrm{~h}$ & 3.593 & 1.188 & 0.014 & 0.009 \\
\hline
\end{tabular}

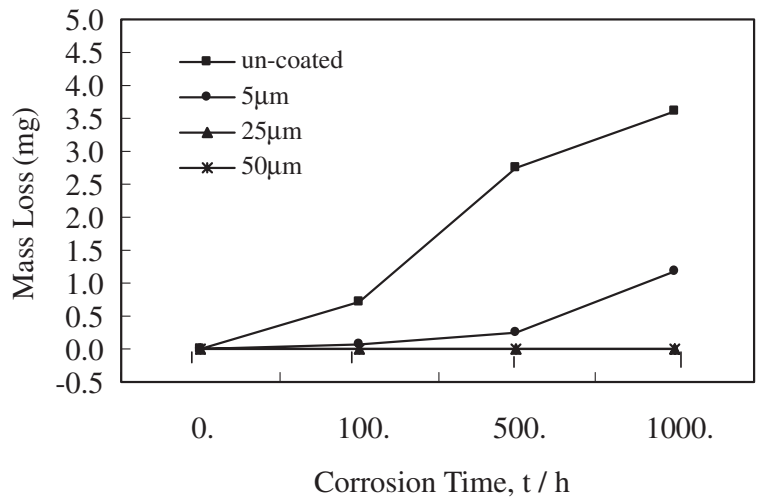

Fig. 6 Relationship of mass loss and corrosion time for Hi-P specimens of 5, 25, $50 \mu \mathrm{m}$ EN coating thickness and uncoated 7075-T6.

corrosion time of the salt spray corrosion test for the uncoated and EN coated specimens and the relationship between the mass loss and the corrosion time is depicted in Fig. 6. For the uncoated material, the corrosion mass loss evidently increased with the increase of the corrosion time. The cause is that the outer surface of the material formed a high density oxidized layer which tends to protect the inner substrate, but it was still corroded to pit by the atmosphere containing $\mathrm{Cl}^{-}$, and continuing pit growth when the corrosion time increases. On the other hand, it indicated that the material with coating $5 \mu \mathrm{m}$ Hi-P EN deposit started to increase the mass loss until 100 -h salt spray corrosion test. The governing factor for the mass loss of $5 \mu \mathrm{m}$ deposit was attributed to the less dense deposit which was prone to the salt spray corrosion therefore the mass loss was gradually aggravated with the increase of the corrosion time. For the deposits of $25 \mu \mathrm{m}$ and $50 \mu \mathrm{m}$ thickness, after the long time (1000-h) corrosion test, having the analogous result that mass loss was negligible for corrosion damage with increasing corrosion time. It revealed that both the coatings were sufficient to protect from corrosion damage under salt spray atmosphere. Figure 7 shows the SEM surface morphology of the specimens through 1000 hours salt spray corrosion. The pictures indicate that the exposed surface of uncoated material obviously showed pitting corrosion distributed throughout the specimen surface (see Fig. 7(a)). After penetration of the surface, the corrosion crevices and flaking often were observed to progress laterally, thereby delaminating layers of material apparently followed the elongated grain boundaries produced during rolling of the plate. On the other hand, the specimen with the EN coatings produced a different pattern of oxidation after 1000-h salt spray corrosion. As shown in Fig. 7(b), the coating surface of $5 \mu \mathrm{m}$ thickness exhibited extensive pitting that extended to the substrate uniformly and masked the orange peel morphology. For the surface in $25 \mu \mathrm{m}$ coating thickness, the irregular pitting and surface oxidation can be clearly identified, as shown in Fig. 7(c). In Fig. 7(d), the coating surface of $50 \mu \mathrm{m}$ thickness had a few such pits or tended to be minor. However, pits in the Hi-P deposits surfaces after 1000-h salt spray exposure had irregular and interconnecting boundaries. The surface roughness of all the thickness of Hi-P deposits after salt spray corrosion was summarized in Table 4 and Fig. 8.

EN is a barrier coating, protecting the substrate by sealing it off from the environment, rather than using sacrificial action. Because of its amorphous nature and passivity, the corrosion resistance of the coating is excellent and, in many environments, superior to that of pure nickel or chromium alloys. $^{25)}$ This investigation can be concluded that Hi-P deposit can improve the corrosion resistance to the salt spray corrosion, in particular, when the thickness of the deposit was greater than $25 \mu \mathrm{m}$.

\subsection{Evaluation of tensile properties and micro-hardness}

Table 5 and Figs. 9 and 10 present the tensile and hardness tests conducted with the substrate both in the uncoated and coated conditions. All represented tensile data in Table 5 were the averaged value of three tests. As it can be seen, the tensile properties of the material are varied as a result of the change of EN coating thickness. That is, the tensile strength and elongation are observed to decrease marginally as the coating thickness increases. Accordingly, internal stress in EN coatings is primarily a function of coating composition, and high phosphorus (more than $10 \% \mathrm{P}$ ) has a compressive stress. The high level of internal stress in these coatings not only promotes cracking and porosity, but also reduce the ductility of the coatings (as elongation). ${ }^{25)}$ In these coatings with Hi-P deposit provide high levels of internal stress and tend to crack under tension test condition. Especially, the coating thickness increased that have a greater tendency to crack. Thicker deposits have the effect on the tensile strength. Tensile stress decreases and shifts to a compressive stress with an increasing $\mathrm{P}$ content. ${ }^{8)}$

In relation to the hardness values for the deposits of different thickness represents the mean value of five 

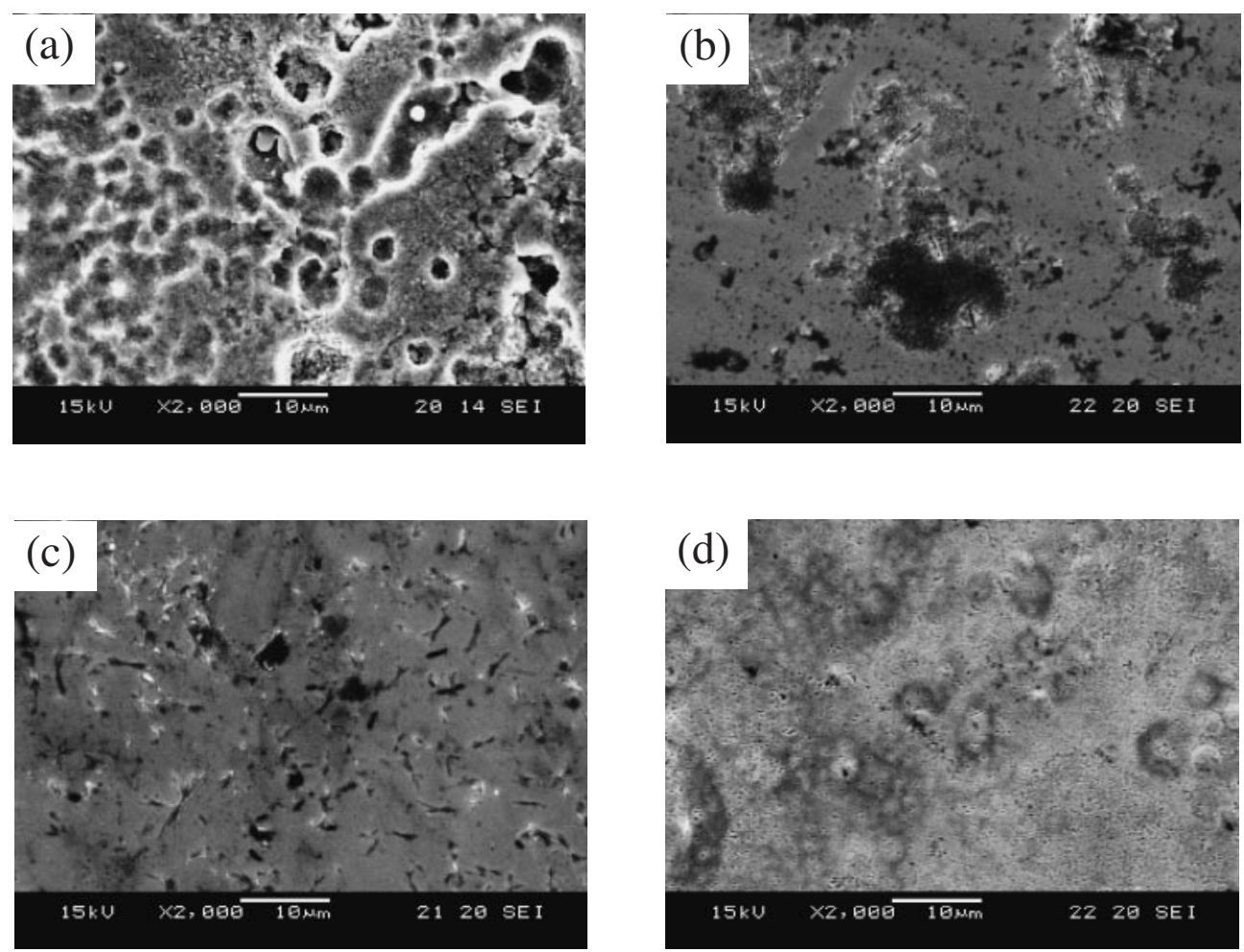

Fig. 7 SEM surface morphology of exposure specimen after 1000-h salt spray corrosion for (a) un-coated, (b) $5 \mu \mathrm{m}$, (c) $25 \mu \mathrm{m}$, (d) $50 \mu \mathrm{m}$.

Table 4 Surface roughness (Ra) of 7075-T6 with and without various EN coating thickness after salt spray test of the different time.

\begin{tabular}{rcccc}
\hline \multirow{2}{*}{$\begin{array}{c}\text { Corrosion } \\
\text { time }\end{array}$} & Un-coated & \multicolumn{3}{c}{ EN coating thickness } \\
\cline { 3 - 5 } & & $5 \mu \mathrm{m}$ & $25 \mu \mathrm{m}$ & $50 \mu \mathrm{m}$ \\
\hline $0 \mathrm{~h}$ & 0.12 & 0.197 & 0.217 & 0.223 \\
\hline $100 \mathrm{~h}$ & 0.232 & 0.199 & 0.218 & 0.223 \\
\hline $500 \mathrm{~h}$ & 0.397 & 0.211 & 0.219 & 0.224 \\
\hline $1000 \mathrm{~h}$ & 0.486 & 0.220 & 0.220 & 0.225 \\
\hline
\end{tabular}

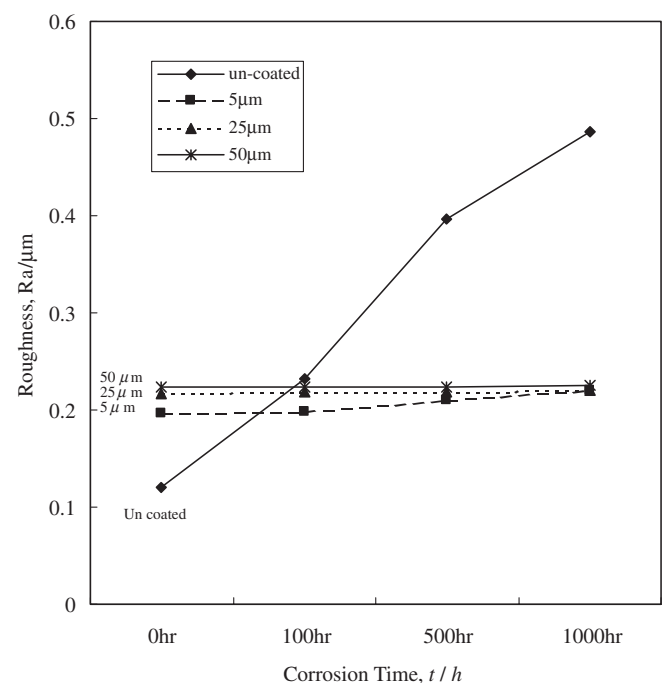

Fig. 8 Surface roughness (Ra) of salt spray corrosion for Hi-P specimens of 5, 25, and $50 \mu \mathrm{m}$ coating thickness and uncoated 7075-T6.
Table 5 Mechanical properties of 7075-T6 with and without various Hi-P EN coating thickness.

\begin{tabular}{ccccccc}
\hline Specimen & $\begin{array}{c}\text { Y.S } \\
(\sigma / \mathrm{MPa})\end{array}$ & $\begin{array}{c}\text { U.T.S } \\
(\sigma / \mathrm{MPa})\end{array}$ & $\begin{array}{c}\text { Elongation } \\
(\%)\end{array}$ & $\mathrm{Hv}, 50 \mathrm{~g}$ & $\begin{array}{c}\text { Ra value } \\
(\mu \mathrm{m})\end{array}$ & $\begin{array}{c}\text { Fatigue } \\
\begin{array}{c}\text { Strength } \\
(\sigma / \mathrm{MPa})\end{array}\end{array}$ \\
\hline Un-coated & 477 & 581 & 10.5 & 186 & 0.120 & 177.8 \\
\hline $5 \mu \mathrm{m}$ & 470 & 579 & 11.0 & 334 & 0.197 & 155.4 \\
\hline $25 \mu \mathrm{m}$ & 463 & 571 & 10.5 & 457 & 0.217 & 153.7 \\
\hline $50 \mu \mathrm{m}$ & 437 & 549 & 10.2 & 606 & 0.223 & 110.6 \\
\hline
\end{tabular}

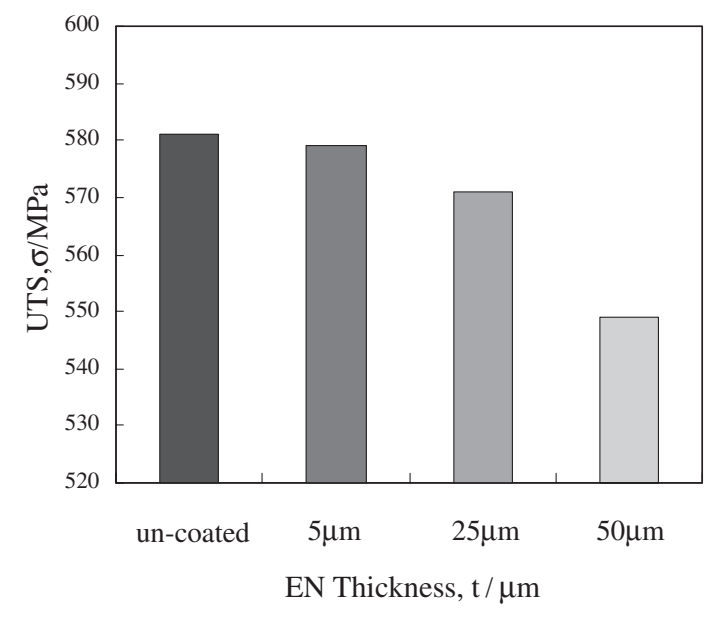

Fig. 9 Effect of EN coating thickness on tensile strength of 7075-T6. 


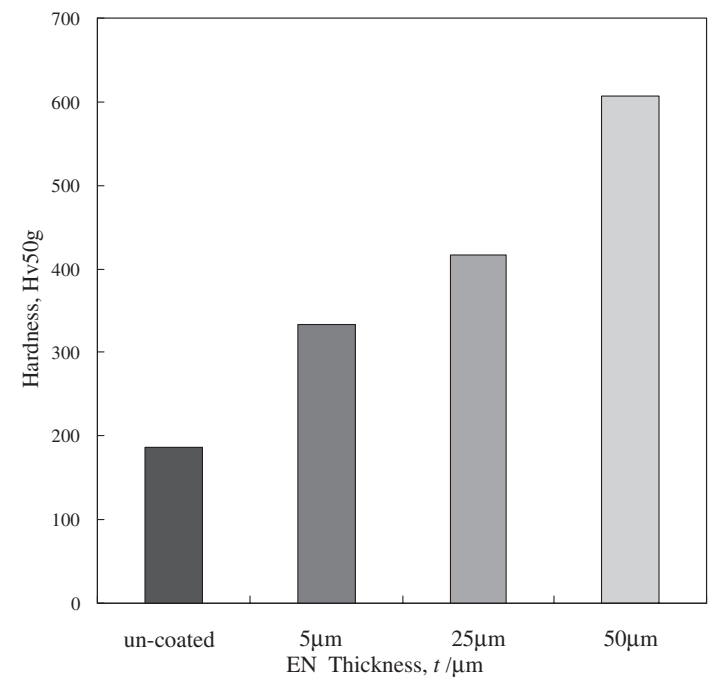

Fig. 10 Effect of coating EN thickness on hardness of 7075-T6.

Table 6 High cycle fatigue strength $(\sigma / \mathrm{MPa})$ of $7075-\mathrm{T} 6$ with and without various thickness Hi-P EN coatings after salt spray test of the different time.

\begin{tabular}{rrrrr}
\hline \multirow{2}{*}{$\begin{array}{c}\text { Corrosion } \\
\text { time }\end{array}$} & Un-coated & \multicolumn{3}{c}{ EN coating thickness } \\
\cline { 3 - 5 } & & $5 \mu \mathrm{m}$ & $25 \mu \mathrm{m}$ & $50 \mu \mathrm{m}$ \\
\hline $0 \mathrm{~h}$ & 177.8 & 155.4 & 153.7 & 110.6 \\
\hline $100 \mathrm{~h}$ & 80.1 & 97.5 & 130.5 & 110.5 \\
\hline $500 \mathrm{~h}$ & 60.1 & 80.4 & 115.2 & 110.4 \\
\hline $1000 \mathrm{~h}$ & 60.0 & 79.5 & 114.0 & 110.3 \\
\hline
\end{tabular}

measurements. According to these results in the as-deposited condition (amorphous), the micro-hardness increased with the increase of the coating thickness, in the range of approximately $330 \sim 600 \mathrm{Hv}_{50 \mathrm{~g}}$. The trend reported in the literature for $\mathrm{EN}$ coatings in the as-deposited condition (amorphous) which indicates a decrease in hardness as the $\mathrm{P}$ content increased. ${ }^{6,26)}$

\subsection{High cycle fatigue (HCF) strength analysis}

Fatigue test specimens were prepared in parallel to the plate rolling direction, which was termed longitudinal (L, rolling direction) specimens. These uncoated and coated specimens were carried out salt spray corrosion of the different time before performing the high cycle fatigue (HCF) test. Table 6 presents the results of HCF tests for the specimens in both the uncoated and coated with 5, 25 and $50 \mu \mathrm{m}$ Hi-P EN deposits after exposed to 100,500 and $1000 \mathrm{~h}$ salt spray corrosion, respectively.

The S-N curves of HCF specimens with and without 1000-h salt spray corrosion of uncoated 7075-T6 and 5, 25 and $50 \mu \mathrm{m}$ Hi-P EN deposits are showed in Figs. 11(a) and (b). Fatigue tests were continued for the maximum run-out sustained was $1.0 \times 10^{7}$ cycles nominally if no failure occurred in three data of specimens. The $\mathrm{S}-\mathrm{N}$ curves for these testing specimens all appear to exhibit the endurance limit, implying infinite life below that stress level. The uncoated (end milled) surface condition produced an apparent endurance limit on the order of $177.8 \mathrm{MPa}$. After salt spray (a)

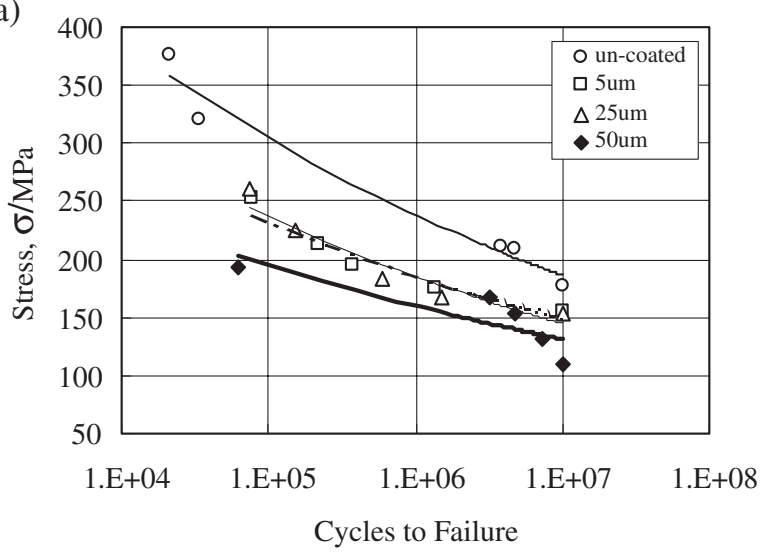

(b)

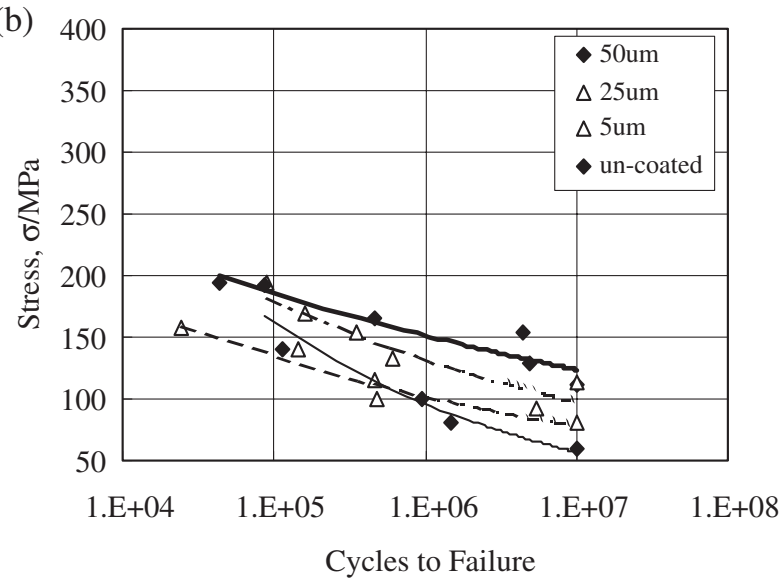

Fig. 11 High cycle fatigue results of uncoated and coated $(5,25,50 \mu \mathrm{m}$ thickness) specimen for (a) no salt spray corrosion, (b) 1000-h salt spray corrosion.

exposure of 1000-h, HCF strength was reduced to nominally $60 \mathrm{MPa}$, one-third that of the original specimen before exposure to salt spray. The fractional loss of fatigue life at stress levels above the endurance limit for salt spray exposed specimens increased rapidly with decreasing maximum stress level, reaching an order of magnitude at the $177.8 \mathrm{MPa}$ endurance limit.

As shown in Figs. 11(a) and (b), all the EN deposits were observed to induce a decrease in the fatigue life, which was marked as the depositing thickness increases. For the specimen with $5 \mu \mathrm{m}$ coating thickness, a fatigue failure occurred at the nominal endurance limit of $79.5 \mathrm{MPa}$ after 1000-h pitting corrosion, half that of the as-deposited specimen without pitting damage. The coated specimens with $25 \mu \mathrm{m}$ and $50 \mu \mathrm{m}$ coating thickness after 1000-h salt spray exposure, the result showed that the fatigue strength was degraded only slight less than that of the original deposited specimens without pitting damage. The magnitude of the reduction, however, depends on the composition, heat treatment, coating thickness as well as original fatigue strength of the substrate. Thicker deposits have the greatest effected on fatigue strength. ${ }^{25)}$ In these tests, the as-deposited conditions were not possible to observe the occurrence of phase changes in the EN deposits to any significant extent, the reduction in fatigue strength produced by EN deposits primarily depended on the coating thickness. 

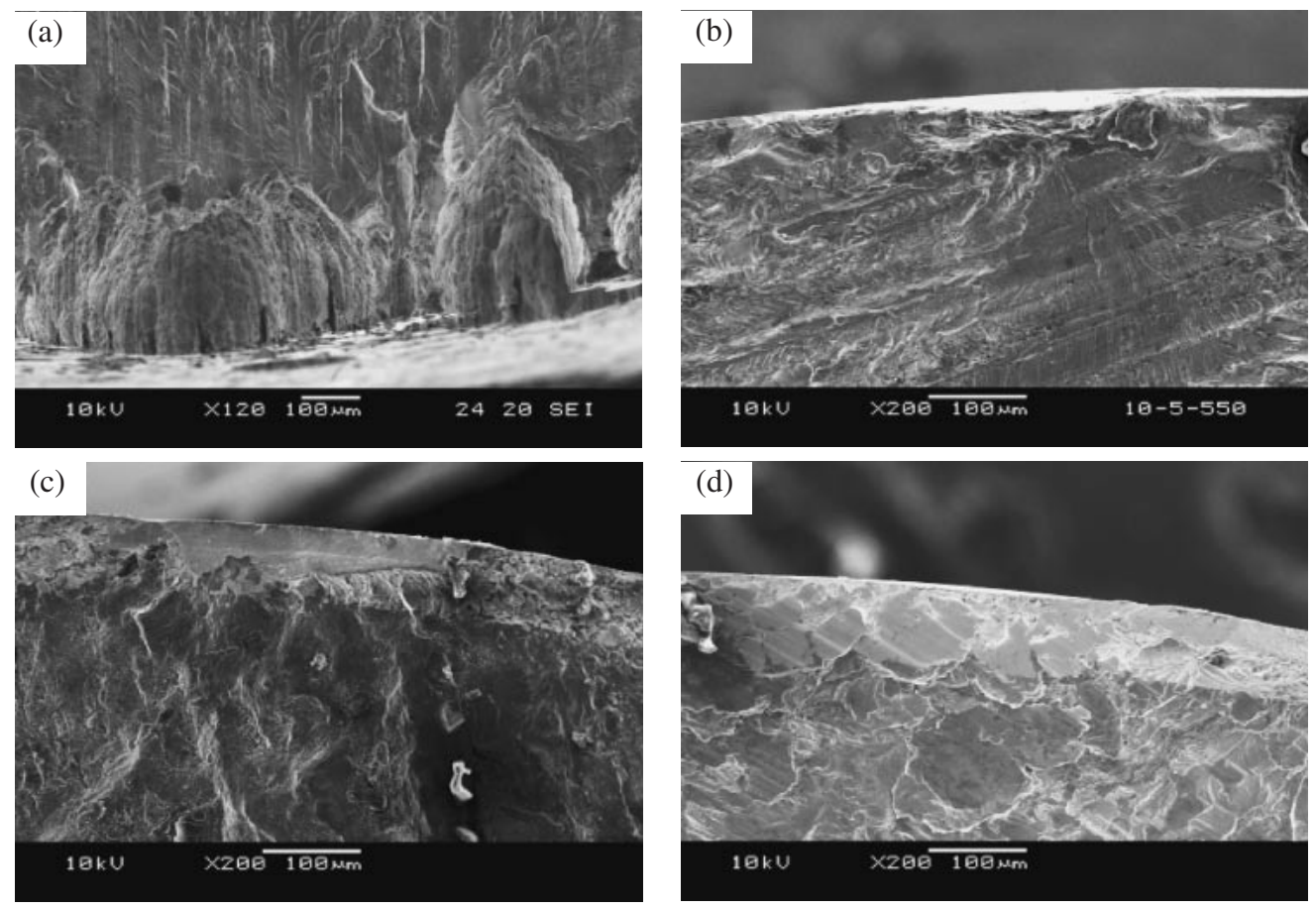

Fig. 13 Fracture surface of fatigue specimen after 1000-h salt spray corrosion for (a) un-coated, (b) $5 \mu \mathrm{m}$, (c) $25 \mu \mathrm{m}$, (d) $50 \mu \mathrm{m}$.

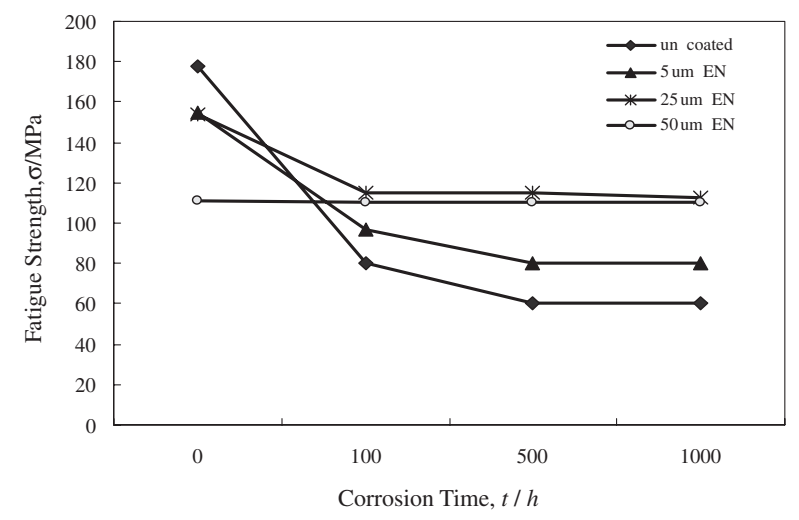

Fig. 12 Effect of EN coating thickness on fatigue resistance of uncoated and coated specimens after salt spray corrosion of the different time.

Figure 12 summarizes the fatigue strength of the three deposits thickness in relation to the corrosion time. As noted early, the mass loss due to the pitting surface condition after salt spray corrosion was proportional to the fatigue strength reduction. According to fracture mechanics, the HCF strength is then inversely proportional to the roughness of surface and the flaw size. The most likely flaws are pits. Variations of the specimen surface conditions were responsible for effects on HCF strength.

\subsection{Fractographic analysis}

Fatigue fracture surfaces of several specimens tested under different stress conditions after 1000-h salt spray corrosion were analyzed by SEM techniques. Fractographic analysis revealed that the fatigue cracking in the uncoated specimens is believed to initiate at the surface. A typical surface fatigue initiation site is showed in Fig. 13(a). All salt spray pitted specimen initiations were exclusively from corrosion pits. In this investigation, the fatigue origins generally exhibited from multiple pits. In the specimens with $5 \mu \mathrm{m}$ thick deposits is believed to initiate at the substrate very close to the substrate-deposit interface as shown in Fig. 13(b).

In contrast, for the specimens with 25 and $50 \mu \mathrm{m}$ thick deposits after 1000-h salt spray corrosion, the cracks are believed to initiate in the deposit itself, since after the fracture of the specimens all the deposits appear to be broken as shown in Figs. 13(c) and (d). In general, it was observed that all the deposits were well adhered to the substrate and independent of their thickness. The fracture surfaces on the deposits were always observed to be brittle, even if the coatings remained in an amorphous condition, which agrees with the previous findings. ${ }^{12,27)}$

\section{Conclusion}

(1) Comparing the Hi-P and Lo-P of EN deposits in $25 \mu \mathrm{m}$ thickness, the corrosion resistance and adhesion strength were concluded that the Hi-P (15\%) deposit is superior to the Lo-P (8\%) deposit in this study.

(2) After 1000-h salt spray corrosion, the mass loss of $25 \mu \mathrm{m}$ and $50 \mu \mathrm{m}$ Hi-P deposits were negligible for corrosion damage, but $5 \mu \mathrm{m}$ Hi-P deposit showed an increase in the mass loss. The governing factor for the mass loss of $5 \mu \mathrm{m}$ deposit was attributed to the less dense deposit which was prone to the salt spray corrosion therefore the mass loss increased with increasing the corrosion time. The test indicated that when the coating thickness is above $25 \mu \mathrm{m}$, the ability of corrosion resistance is evidently effective.

(3) In these coatings with Hi-P EN deposit provide high levels of internal stress and tend to crack under tension 
test condition. Especially, the coating thickness increased that have a greater tendency to crack. Thicker deposits have a harmful effect on the tensile strength. Tensile stress decreases and shifts to a compressive stress with an increasing P content.

(4) Thicker deposits have the more influence on fatigue strength. The reduction in fatigue strength produced by EN deposits was governed by the coating thickness and the mass loss due to the pitting surface condition after salt spray corrosion. According to fracture mechanics, the HCF strength is then inversely proportional to the roughness of surface and the flaw size.

(5) After 1000-h salt spray corrosion, the fatigue cracks in the uncoated specimen initiated at the surface and exclusively from corrosion multiple pits. The specimen coated EN deposit of $5 \mu \mathrm{m}$ thickness, the fatigue cracks initiated at the substrate very close to the substratedeposit interface. With 25 and $50 \mu \mathrm{m}$ deposits, the cracks are believed to initiate in the deposit itself, since after the fracture of the specimens all the deposits appear to be broken.

\section{REFERENCES}

1) ASM Handbook, Vol. 19, Fatigue and Fracture, S. R. Lampman, ed., (ASM International, Metals Park, OH, 1996) pp. 596-597.

2) P. Prevéy and J. Cammett: "Low Cost Corrosion Damage Mitigation and Improved Fatigue Performance of Low Plasticity Burnished 7075 T6," JMEP, 10(5), (ASM International, Materials Park, OH, Oct. 2001) pp. $548-555$.

3) J. Cammett and P. Prevéy: "Fatigue Strength Restoration in Corrosion Pitted 4340 Alloy Steel via Low Plasticity Burnishing," (2001), Retrieved July 19, 2002, from http://www.lambda-research.com/ publica.htm.

4) I. J. Polmear: Light Alloys-Metallurgy of light metals, Third edition, (Arnold London, 1995) pp. 42-65.
5) V. Agarawala: Corrosion and Aging: Aircraft Concerns, presentation at 11th Annual AeroMat Conference, (Bellevue, WA, June 26-29, 2000) pp. 1-46.

6) J. A. Berríos, M. H. Staia, E. C. Hernández, H. Hintermann and E. S. Puchí: Surf. Coatings Technol. 108-109 (1998) 466-472.

7) H. Spähn: Trans. Inst. Metal Finish. 42 (1964) 364.

8) K. Parker and H. Shah: Plating 58 (1971) 230.

9) V. S. Borisov and S. A. Vishenkov: Chemical Nickel Plating 2 (1958) 37.

10) E. W. Turns and J. W. Browning: Plating 60 (1975) 175

11) K. Stallman and H. Speckhardt: Metalloberfl. Agnew. Elektrochem. 35(10) (1981) 979.

12) Y. Z. Zhang, Y. Y. Wu and M. Yao: J. Mater. Sci. Lett. 15 (1995) 1364.

13) H. Izumi, H. Sunada and Y. Konodo: J. Soc. Mater. Sci. Jpn. 24 (1975) 320.

14) E. S. Puchi, M. H. Stara, H. Hintermann, A. Perturz and J. A. Chitty: Thin Solid Films 290-290 (1996) 370.

15) J. A. Chitty, M. H. Staia, A. Pertuz, H. Hintermann and E. S. Puchi: Thin Solid Films 308-309 (1997) 430.

16) R. J. Keyse and C. Hammond: Mater. Sci. Technol. 3 (1987) 963.

17) ASTM E 466-96: Standard Practice for Conducting Force Controlled Constant Amplitude Axial Fatigue Tests of Metallic Materials 1, 03.01 (1996) pp. 466-470.

18) ASTM E 8M-97: Standard Test Methods for Tension Testing of Metallic Materials [Metric], 03.01 (1997) pp. 77-97.

19) J. Sekler, P. A. Steinman and H. E. Hintermann: Surf. Coating Technol. 36 (1988) 519-529.

20) T. Arai, H. Fujita and M. Watanabe: Thin Solid Films 154 (1987) 387401.

21) ASTM G 85-94: Standard Practice for Modified Salt Spray (Fog) Testing, (1994) 357-362.

22) ASTM B 117-95: Standard Practice for Operating Salt Spray (Fog) Apparatus, (1995) pp. 1-8.

23) R. Bantle and A. Matthews: Surf. Coating Technol. 74-75, (1995) 857868.

24) R. J. Keyse and C. Hammond: Mater. Sci. Technol. 3 (1987) 963.

25) Metals Handbook ninth Edition Volume 5, Surface Cleaning Finishing, and Coating, pp. 219-243.

26) W. Rediel: Electroless Nickel Plating, (ASM International, Metals Park, OH, 1991) p. 181.

27) Y. Y. Wu, Y. Z. Zhang and M. Yao: Plating Surf. Finish. 42 (1995) 83. 